\title{
DEVELOPMENT OF A UV/VIS SPECTROPHOTOMETRIC METHOD FOR ANALYSIS OF TOTAL POLYPHENOLS FROM Caesalpinia peltophoroides BENTH.
}

\author{
Fernanda G. Bueno, Maria A. D. Machareth, Gean P. Panizzon, Gisely C. Lopes e João C. P. Mello* \\ Departamento de Farmácia, Universidade Estadual de Maringá, Av. Colombo, 5790, 87020-900 Maringá - PR, Brasil \\ Eneri V. S. Leite-Mello \\ Departamento de Ciências Morfológicas, Universidade Estadual de Maringá, Av. Colombo, 5790, 87020-900 Maringá - PR, Brasil
}

Recebido em 23/8/11; aceito em 3/11/11; publicado na web em 4/1/12

\begin{abstract}
Caesalpinia peltophoroides is a domesticated tree found in Brazil. It was necessary to develop an analytical method to determine the content of total polyphenols (TP) in this herbal drug. The pre-analytical method was standardized for analysis time, wavelength, and the best standard to use. The optimum conditions were: pyrogallol, $760 \mathrm{~nm}$, and $30 \mathrm{~min}$ respectively. Under these conditions, validation by UV/Vis spectrophotometry proved to be reliable for TP of the crude extract and semipurified fractions from $C$. peltophoroides. Standardization is required for every herbal drug, and this method proved to be linear, precise, accurate, reproducible, robust, and easy to perform.
\end{abstract}

Keywords: Caesalpinia peltophoroides; total polyphenols; UV/VIS spectroscopy validation.

\section{INTRODUCTION}

The family Fabaceae contains the second-largest number of medicinal plants worldwide. ${ }^{1}$ In Brazil, the family includes over 210 genera and 2694 species. $^{2}$ One of its members, Caesalpinia peltophoroides Benth. is popularly known as "sibipiruna" or "false Brazil wood", and is sometimes reported as Caesalpinia pluviosa var. peltophoroides (Benth.) G.P. Lewis. ${ }^{3}$ It is a domesticated tree, which in Brazil is found mainly in the Atlantic Forest and the Pantanal. C. peltophoroides is used as an ornamental tree in cities and has a potential use for timber, ${ }^{4}$ and in Bolivia the bark is popularly used to treat dysentery. ${ }^{5}$ Previous studies using a $70 \%$ ethanol extract from the bark of $C$. peltophoroides showed in vitro antimalarial activity against chloroquine-resistant Plasmodium falciparum, with an $\mathrm{IC}_{50}$ of $8.3 \mu \mathrm{g} / \mathrm{mL}$. ${ }^{6}$ In recent studies in vitro and in vivo against the same agent, using a $50 \%$ ethanol extract of the bark, our group found an $\mathrm{IC}_{50}$ of $3.41 \mu \mathrm{g} / \mathrm{mL}$, and confirmed the presence of quercetin by mass spectrometry. $^{7}$

The Folin-Ciocalteu method is widely used to determine total polyphenols. This reaction occurs by the phosphotungstic acid reduction, forming a blue chromophore constituted by a phosphotungstic-phosphomolybdenum complex. ${ }^{8,9}$ The maximum absorption of this chromatophore depends on the $\mathrm{pH}$ of the solution and the concentration of phenolic compounds. ${ }^{8}$ Cicco et al. ${ }^{10}$ considered this to be a generalized technique, because some specific details may be modified, ${ }^{9,11}$ such as the amount of Folin-Ciocalteu reagents and the sequence in which they are added, sodium-carbonate concentration, wavelength, the standard used, time period, and temperature. Modifications of this method are found in several pharmacopeias ${ }^{12-14}$ and laboratory routines. ${ }^{10,15,16}$ Considering the variations in this method, the present study aimed to develop a standard procedure for the pre-analytical method and analytical validation for the determination of total polyphenols in the crude extract from Caesalpinia peltophoroides bark.

\section{EXPERIMENTAL}

\section{Reagents and standards}

The solvents used were: ethanol (Cereálcool $\left.{ }^{\circledR}\right)$, Folin-Ciocalteu $\left(\right.$ Dynamics $\left.^{\circledR}\right)$, ethyl acetate $\left(\right.$ Synth $\left.^{\circledR}\right)$, methanol (Mallinckrodt $\left.{ }^{\circledR}\right)$, anhydrous sodium carbonate $\left(\mathrm{Nuclear}^{\circledR}\right)$, and the standards gallic acid (98\%), tannic acid (purissimum), catechin (98\%), and pyrogallol $(99 \%)$ (all from Sigma ${ }^{\circledR}$ ).

\section{Plant material and preparation of extracts}

Samples of Caesalpinia peltophoroides bark were collected at the Universidade Estadual de Maringá, Maringá, Paraná, Brazil. A voucher specimen was deposited at the UEM herbarium under number HUEM 12492. IBAMA-SISBIO gave permission for this collection under a license granted to J. C. P. de Mello (No. 11995-2, 03/12/2008). The bark $(2 \mathrm{~kg})$ was dried under forced-air circulation and then milled in a Tigre ASN-5 stainless-steel hammer mill. The milled bark $(1.5 \mathrm{~kg} ; 10 \%$ $\mathrm{w} / \mathrm{v}$ ) was extracted in $50 \%$ ethanol by turbo-extraction (Ultra-Turrax, UTC115KT, $15 \mathrm{~min} ; \mathrm{t}<40^{\circ} \mathrm{C}$ ). The crude extract was concentrated in a rotavapor under reduced pressure and lyophilized (CE; $150 \mathrm{~g}$ ). $\mathrm{CE}(50 \mathrm{~g})$ was dissolved in water $(500 \mathrm{~mL})$ and partitioned with ethyl acetate $(10 \times 500 \mathrm{~mL})$, resulting in two semipurified fractions: ethylacetate fraction (EAF) and aqueous fraction (AQF). The EAF (3 g) was fractioned employing a chromatography column (h: $15 \mathrm{~cm} \varnothing$ : $2.5 \mathrm{~cm}$ ) containing Sephadex ${ }^{\circledR}$ LH-20 as the stationary phase. 50\% ethanol $(500 \mathrm{~mL}), 100 \%$ ethanol $(400 \mathrm{~mL}), 50 \%$ methanol $(300 \mathrm{~mL})$, $100 \%$ methanol $(300 \mathrm{~mL})$ and $70 \%$ acetone $(300 \mathrm{~mL})$ as the mobile phase were used, resulting in five fractions: F1 (2.17 g), F2 (0.21 g), F3 (0.06 g), F4 (0.17 g), and F5 (0.08 g).

\section{Pre-analytical method standardization for determination of total polyphenols (TP)}

The standardization of the method was carried out prior to the validation process, using the standards and $\mathrm{CE}$ of $C$. peltophoroides, to evaluate three parameters: reaction kinetics, maximum absorption wavelength, and the standard that best fits the $\mathrm{CE}$ of $C$. peltophoroides. 
<smiles>O=C(O)c1cc(O)c(O)c(O)c1</smiles><smiles>O=C(Oc1cc(O)c(O)c(C(=O)Oc2cc(O)c(O)c(O)c2)c1)c1cc(O)c(O)c(OC(=O)c2cc(O)c(O)c(OC(=O)c3cc(O)c(OC(=O)c4cc(O)c(O)c(OC(=O)c5cc(O)c(O)c(C(=O)Oc6cc(O)c(O)c(O)c6)c5)c4)c(OC(=O)c4cc(O)c(O)c(OC(=O)c5cc(O)c(O)c(O)c5)c4)c3)c2)c1</smiles>

Figure 1. Chemical structure of standards: (A) gallic acid, (B) tannic acid, (C) catechin, and (D) pyrogallol

The method described by the European Pharmacopoeia ${ }^{12}$ for determination of TP was used as a guideline for the dilution of the CE and standards (gallic acid, tannic acid, catechin, and pyrogallol) (Figure 1). We used a solution of $10.75 \%$ anhydrous sodium carbonate.

Stock solutions of each standard (gallic acid, tannic acid, catechin and pyrogallol, $25 \mu \mathrm{g} / \mathrm{mL})$ and $\mathrm{CE}(200 \mu \mathrm{g} / \mathrm{mL})$ were prepared in distilled water. Two milliliters of each solution was transferred to a $25-\mathrm{mL}$ flask containing distilled water $(10 \mathrm{~mL})$ and Folin-Ciocalteu ( $1 \mathrm{~mL})$. The volume was completed with $10.75 \%$ anhydrous sodium carbonate $(\mathrm{w} / \mathrm{v})$, resulting in final concentrations of $2 \mu \mathrm{g} / \mathrm{mL}$ of each standard and $16 \mu \mathrm{g} / \mathrm{mL}$ of CE. The samples were scanned in a UV/Vis spectrophotometer (Shimadzu PC-1650) beginning 10 to $40 \mathrm{~min}$ after the addition of the sodium-carbonate solution, and scanning from 400 to $800 \mathrm{~nm}$ at intervals of $2 \mathrm{~min}$ between each reading, to determine the spectra. Distilled water was used as a blank. The kinetic reaction was verified comparing the absorbance percentage increase of each solution, for the wavelengths of $691,{ }^{15} 715,{ }^{13} 760,{ }^{12}$ and $800 \mathrm{~nm}$. This percentage increase was calculated by dividing the difference in absorbance between two wavelengths by the mean absorbance of the shorter wavelength and multiplying by 100 . The reaction times were observed and compared statistically, using the percentage increase between the times $(10,20,30$, and $40 \mathrm{~min})$.

To determine the best standard to characterize the $\mathrm{CE}$ from $C$. peltophoroides, the molar absorptivity of each standard and the $\mathrm{CE}$ was calculated by the equation: $\mathrm{A}=\varepsilon . \mathrm{bc}$, where $\mathrm{A}=$ sample absorbance $(\mu \mathrm{g} / \mathrm{mL}) ; \varepsilon=$ molar absorptivity $(\mathrm{mol} / \mathrm{L}) ; \mathrm{b}=$ thickness of the cell $(\mathrm{cm}) ; \mathrm{c}=$ sample concentration $(\mathrm{g} / 100 \mathrm{~mL}) \cdot{ }^{13,17}$

\section{Analytical method validation}

For validation of the analytical method, the guidelines established by the ICH (International Conference on the Harmonization of Technical Requirements for the Registration of Pharmaceuticals for Human Use) and by Brazilian regulation RE No. 899/2003 of the National Health Surveillance Agency (ANVISA) were employed. ${ }^{18}$
The standardized method, with a reaction time of $30 \mathrm{~min}$, wavelength of $760 \mathrm{~nm}$ and pyrogallol as the standard, was used to validate the method for the determination of total polyphenols. Analyses were performed in triplicate.

\section{Curve of the standard and CE linearity}

The calibration curve of the pyrogallol standard (1.6 to $4.8 \mu \mathrm{g}$ / $\mathrm{mL}$ ) and CE linearity (6.49 to $26.93 \mu \mathrm{g} / \mathrm{mL}$ ) were determined from five concentration points over the range of concentrations $(0.32$ to $32.45 \mu \mathrm{g} / \mathrm{mL}$ ), following the Lambert-Beer law. The slope and other statistics of the calibration curves were calculated by linear regression, with the software Statistica ${ }^{\circledR} 8.0$.

\section{Limits of detection and quantitation}

The limits of detection (LOD) and quantitation (LOQ) were calculated from the relationship between the standard deviation (SD) of the $\mathrm{CE}$ linearity and the slope, using the appropriate multiplier.

\section{Precision}

Precision was evaluated at two levels: repeatability (intra-day) and intermediate (inter-day) precision, where the SD and relative standard deviation (RSD) of six replicates $(16.23 \mu \mathrm{g} / \mathrm{mL})$ were considered. An RSD over $5 \%$ was considered unacceptable.

\section{Accuracy}

The accuracy was evaluated based on the recovery, following the addition of 1,2, or $3 \mathrm{mg}$ of pyrogallol in the linearity solution. To determine the recovery, the values determined from the calibration curve of the standard and the linearity of the CE were used as the expected absorbance, and transformed into the expected TP content.

\section{Specificity and selectivity}

Specificity and selectivity were determined during the pre-validation, by adding pyrogallol $(3.2 \mathrm{mg})$ to the linearity solutions of the $\mathrm{CE}$, and comparing with $\mathrm{CE}$ linearity. 


\section{Robustness}

With regard to robustness, the stability of the solution under the influence of natural light and $\mathrm{pH}(14.06$ and $7.5 \%(\mathrm{w} / \mathrm{v})$ anhydrous sodium carbonate solutions) was evaluated. Following the validation, the PT in the CE and semipurified fractions (EAF, AQF, and F1-F5) was determined.

\section{Statistical analyses}

The statistical analyses were performed using Statistica ${ }^{\circledR} 8.0$ (StatSoft Copyright, Inc.). Results were expressed as mean \pm SD [RSD $(\%)]$ and were analyzed using ANOVA. Significant differences from the control group were determined by Dunnett's test, with $P$ $<0.05$ as the significance criterion. Tests for linear correlation and residual analysis were performed by simple linear regression and the residual " $r$ " was set as equal to or greater than 0.99 .

\section{RESULTS AND DISCUSSION}

Molecular absorption spectrophotometry in ultraviolet/visible light (UV/VIS) is an analytical method based on the property of an ion or molecular species to absorb at certain wavelengths of UV/VIS radiation. In the process of absorbing the radiation, the energy of the photons is transferred to the molecules of the medium under analysis to cause electron transitions associated with vibrational and rotational transitions. ${ }^{19}$ Having in mind that the energy levels of the molecules are quantum, only those wavelengths whose photons have identical energy to an allowed transition are absorbed. Thus, the absorption can be considered as a specific process related to the structure of the absorbing species, which determines the energy involved in the electron transition. However, to make the method more selective, normally reagents are used to convert the species of interest into a form that allows the absorption of the radiation to be measured with greater sensitivity and/or selectivity. ${ }^{20}$

The development of less onerous methods, easier to execute and normally using less complex apparatus, requires validation studies of these techniques for each plant species, in order to assure the reliability of the results. ${ }^{21}$ In general, the methodologies have not provided coherent results when used for different families, genera and even species of plants, that contain the same groups of substances in their composition. Therefore, the first-order kinetics, wavelength, and molar absorptivity of the reference substance must be evaluated, as a prerequisite for the selectivity of the method under development.

The European Pharmacopoeia ${ }^{12}$ indicates a single general method for determination of total polyphenols in all herbal drugs. The Brazilian Pharmacopeia ${ }^{12}$ method provides a monograph for each plant, describing different techniques for quantifying total polyphenols. These variations consist of the reading time (2 to 30 min), wavelength (691 to $760 \mathrm{~nm}$ ), amount of Folin-Ciocalteu, the standards used, and sodium carbonate concentration. The use of an individually developed method for each herbal drug serves to reduce the influence of the presence of other phenolic compounds on the final content and increase the specificity of the method, and is therefore more accurate than the more general methods recommended in other pharmacopeias. ${ }^{12,14}$ However, not all herbal drugs are described in the Brazilian Pharmacopeia. ${ }^{13}$ It is necessary to standardize and validate the analysis method for each herbal drug.

In the pre-analysis standardization technique for determination of total polyphenols, all the standards $(2 \mu \mathrm{g} / \mathrm{mL})$ and CE $(16 \mu \mathrm{g} / \mathrm{mL})$ were used. It was necessary to establish the differences among the standards because the CE contains several substances that may affect the concentration of total polyphenols. If the standard were used in the same concentration as the CE, it would show an absorbance above the linear range. Figure 2 shows the reaction kinetics of the standards and $\mathrm{CE}$, determined by scanning the samples at different wavelengths $(691,715,760$, and $800 \mathrm{~nm})$. The increase in percentage absorbance between the wavelengths of 691-715 and 715-760 was significant for the standards and $\mathrm{CE}$, as follows: gallic acid $\mathrm{F}_{60,3}=1081.9$; tannic acid $\mathrm{F}_{60,3}=1213.8$, catechin $\mathrm{F}_{60,3}=1033.2$; pyrogallol $\mathrm{F}_{60,3}=3442.9$, and $\mathrm{CE}$ $\mathrm{F}_{60,3}=5984.4, P<0.05$. Between the wavelengths of 760-800 for the standard, the increase was significant, but less than $5 \%$ compared to the value obtained at $760 \mathrm{~nm}$. For the CE there was a decrease between $760-800 \mathrm{~nm}$. Comparing the reaction time for phosphotungstic acid reduction (10 to $40 \mathrm{~min}$ ), there was no significant difference between the values $(P>0.05)$. The reaction kinetics with respect to the increase in percentage and wavelengths were similar for pyrogallol and CE. According to Glas $1^{15}$ each substance has a characteristic variation in the absorption at different wavelengths, and similar reaction kinetics should occur in substances with similar structures.
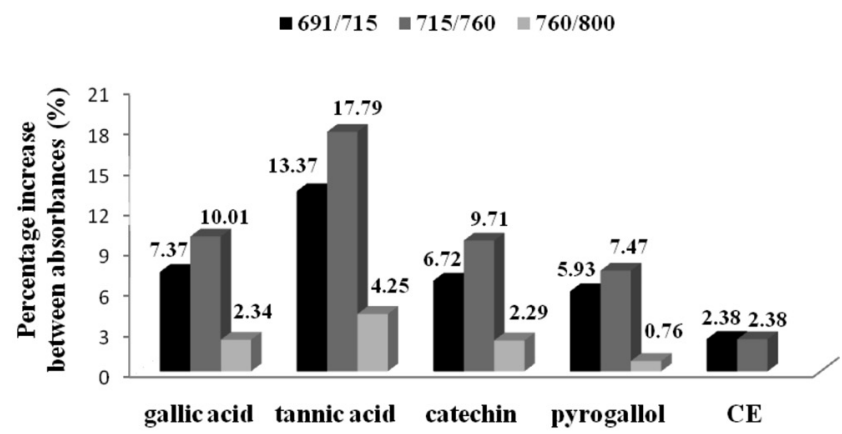

Figure 2. Percentage increase in the mean absorbances of the raw extract and the standards, of the longer compared to the next shorter wavelength $(691,715,760$, and $800 \mathrm{~nm})$

The Folin-Ciocalteu method shows a response proportional to the number of phenolic groups, forming a blue complex that is proportional to the number of hydroxyl groups on the aromatic ring. ${ }^{22,23}$ The structure and activity of phenolic compounds are related to the number of hydroxyl groups on the aromatic ring. ${ }^{22}$ The standard molecules analyzed have different structures, and pyrogallol has the most hydroxyl groups attached to the aromatic ring, proportional to its mass. This can be observed by the molar absorptivity, as shown by the Lambert-Beer Law, which relates the absorbance and molar concentration of the analyte. ${ }^{17} \mathrm{~A}$ high absorptivity demonstrates the capacity of the chromophore to absorb light in certain conditions, and the higher this value, the more precise will be the determination of absorbance. ${ }^{13}$ With more hydroxyl groups linked to the aromatic ring, pyrogallol has similar reaction kinetics to $\mathrm{CE}$, and is therefore considered the best standard for the determination of TP for this herbal drug. Table 1 shows the variations that can occur in estimates of the total polyphenol content based on standards with different molar absorptivities and reaction kinetics, demonstrating that the use of an inappropriate standard can lead to error.

Pre-analytical standardization of the method for the CE of C. peltophoroides indicated that the best wavelength to use is $760 \mathrm{~nm}$. For

Table 1. Comparison among the molar absorptivity of the standards and total polyphenol content of the crude extract of $C$. peltophoroides

\begin{tabular}{ccc}
\hline Samples & Molar absorptivity & TP $(\%)$ \\
\hline Gallic acid & 975.0 & 41.74 \\
Tannic acid & 802.6 & 57.63 \\
Catechin & 1191.0 & 40.98 \\
Pyrogallol & 1438.7 & 22.19 \\
\hline
\end{tabular}


different reaction times (10-40 min) with Folin-Ciocalteu, no significant difference among the absorbances of the $\mathrm{CE}$ and the standards was observed. Therefore, to carry out the validation, the method described in the European Pharmacopoeia ${ }^{12}$ was followed, using an analysis time of $30 \mathrm{~min}$, absorbance of $760 \mathrm{~nm}$, and pyrogallol as the standard.

The analysis curves obtained for pyrogallol $(\mathrm{y}=0.1277 \mathrm{x}+$ $0.0421, r=0.999)$ and CE linearity $(y=0.03 x+0.0089, r=0.999)$ showed that the method is linear over the concentrations examined and for the response obtained by the apparatus. This is observed from the linear correlation coefficient " $r$ " which has a value greater than 0.99, as allowed by RE No. 899. ${ }^{18}$ The value of $\mathrm{F}$ found for the model was greater than the critical $\mathrm{F}$ value, and the reverse for the lack of fit of adjustment. From the linear equation obtained, the detection and quantification limits were estimated as concentrations of 0.23 and $0.75 \mu \mathrm{g} / \mathrm{mL}$, respectively.

With respect to precision, the variation coefficients of repeatability $(0.36 \%)$ and intermediate precision $(0.05 \%)$ show that the results were within the limits allowed by law, with a residual standard deviation of up to $5 \% .{ }^{18}$ There was no statistical difference in the intra-day and inter-day tests, with $P>0.05$ ( 0.87 and 0.42 , respectively). Accuracy is considered the most important aspect of the analysis, indicating the effect of variations in a laboratory due to factors such as different days, analysts, or apparatus, thereby ensuring that the method is reproducible. ${ }^{18,24}$

With respect to robustness (Table 2), the values found for the different variations in the method were similar. However, the samples prepared with a $14.06 \%$ solution of anhydrous $\mathrm{Na}_{2} \mathrm{CO}_{3}$ were statistically different $(P<0.05)$ from those prepared with $10.75 \%$ anhydrous $\mathrm{Na}_{2} \mathrm{CO}_{3}$. The remaining samples, in the presence of light and with a $7.5 \%$ anhydrous $\mathrm{Na}_{2} \mathrm{CO}_{3}$ solution, showed no statistical differences $(P>0.05)$ from $10.75 \%$ anhydrous $\mathrm{Na}_{2} \mathrm{CO}_{3}$. An increased quantity of sodium carbonate may mean a decreased percentage of total polyphenols. The use of sodium carbonate decahydrate was recommended by the European Pharmacopoeia ${ }^{12}$ whereas anhydrous sodium carbonate was used in this study. Accuracy is considered as the degree of agreement, i.e., the nearness to a true result, the calibration curve, and the findings of the trial. One method is to evaluate the accuracy by adding a standard at three different levels of concentration. The standard addition method is often used in cases where no blank matrix is prepared, for example, in the case of extracts, where the matrices are complex and unknown. ${ }^{21}$

Table 2. Levels of total polyphenols (TP) in samples obtained with two modifications of the method: presence or absence of light, and concentrations of 7.5 and $14.06 \%$ anhydrous $\mathrm{Na}_{2} \mathrm{CO}_{3}$

\begin{tabular}{cc}
\hline Method modifications & $\mathrm{TP}(\%)(\mathrm{x} \pm \mathrm{SD}[\mathrm{RSD}])$ \\
\hline Original sample & $22.02 \pm 0.08[0.34]$ \\
Anhydrous $\mathrm{Na}_{2} \mathrm{CO}_{3} 7.5 \%(\mathrm{w} / \mathrm{v})$ & $22.10 \pm 0.09[0.40]$ \\
Anhydrous $\mathrm{Na}_{2} \mathrm{CO}_{3} 14.06 \%(\mathrm{w} / \mathrm{v})$ & $21.18 \pm 0.07[0.34]$ \\
Presence of light & $22.05 \pm 0.11[0.49]$ \\
\hline
\end{tabular}

$\mathrm{x}=$ mean; $\mathrm{SD}=$ standard deviation; $\mathrm{RSD}(\%)$ = relative standard deviation

In the case of complex matrices, if the matrix without the analyte is not available, the effects of the matrix system can be tested by comparing the slopes of linearity and specificity. ${ }^{18,24,25}$ If the curves are parallel, we can affirm that the method is selective. ${ }^{24}$ The selectivity of the method for CE $(y=0.029+0.137, r=0.999)$ was confirmed by superimposing the analytical curves (Figure 3 ). The sample recovery was used to determine the accuracy, and we obtained a variation from 98.08 to $103.21 \%$, showing that the method is accurate for the complex matrix.

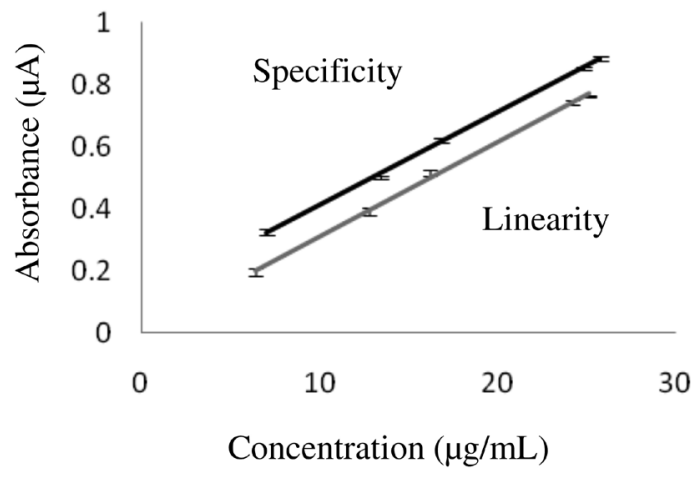

Figure 3. Comparison between specificity and linearity curve of the crude extract of $C$. peltophoroides

Following the demonstration of the method's validity, we determined the percentage of TP for the extracts and fractions, as follows: CE (22.74 \pm 0.01 [1.23]), EAF (27.98 \pm 0.52 [1.98]), AQF (26.16 \pm 0.50 [1.81]), F1 (42.84 \pm 0.01 [1.23]), F2 (22.83 \pm 0.01 [1.23]), F3 (33.78 \pm 0.52 [1.53]), F4 (48.67 \pm 0.67 [1.38]), and F5 (31.21 \pm 0.31 [0.99]).

\section{CONCLUSIONS}

In this study, the estimated concentration of total polyphenols changed when changes were made in the reaction time, wavelength, and the standard, demonstrating that it is necessary to standardize the method for each herbal drug. To quantify total polyphenols in the extract from C. peltophoroides, the method described by the European Pharmacopoeia ${ }^{12}$ proved to be efficient, meeting the requirements for a valid technique. The reference substance that provided the best reliability of the analytical method for this herbal drug was pyrogallol.

\section{ACKNOWLEDGMENTS}

We thank CAPES, CNPq Fundação Araucária, INCT_if, and FINEP for financial support. The technical assistance provided by A. Arantes and C. R. Novello is gratefully acknowledged. Our gratitude to Dr. J. W. Reid for revising the English text. The valuable observations of anonymous reviewers contributed significantly to improvements in the manuscript.

\section{REFERENCES}

1. Gao, T.; Yao, H.; Song, J.; Liu, C.; Zhu, Y.; Ma, X.; Pang, X.; Xu, H.; Chen, S.; J. Ethnopharmacol. 2010, 130, 116.

2. http://floradobrasil.jbrj.gov.br/2010, accessed March 2011.

3. http://floradobrasil.jbrj.gov.br/2010/FB018164, accessed January 2011.

4. Corte, V. B.; Borges, E. E. L.; Ventrella, M. C.; Leite, I. T. A.; Braga, J. T.; Rev. Árvore 2008, 32, 641.

5. Deharo, E.; Bourdy, G.; Quenevo, C.; Muñoz, V.; Ruiz, G.; Suvain, M.; J. Ethnopharmacol. 2001, 77, 91.

6. Baelmans, R.; Deharo, E.; Bourdy, G.; Muñozv, V.; Quenevo, C.; Sauvain, M.; Ginsburg, H.; J. Ethnopharmacol. 2000, 73; 271.

7. Kayano, A. C. A. V.; Lopes, S. C. P.; Bueno, F. G.; Cabral, E. C.; SouzaNeiras, W. C.; Yamauchi, L. M.; Foglio, M. A.; Eberlin, M. N.; Mello, J. C. P.; Costa, F. T. M.; Malar. J. 2011, 10, 112.

8. Schofield, P.; Mbugua, D. M.; Pell, A. N.; Anim. Feed Sci. Technol. 2001, 91, 21.

9. Gülçin, I.; Sat, I. G.; Beydemir, S.; Elmastas, M.; Küfrevio lu, Ö. I.; Food Chem. 2004, 87, 393.

10. Cicco, N.; Lanorte, M. T.; Paraggio, M.; Viggiano, M.; Lattanzio, V.; Microchem. J. 2009, 91, 107. 
11. Andrade, C. A.; Costa, C. K.; Bora, K.; Miguel, M. D.; Miguel, O. G.; Kerber, V. A.; Rev. Bras. Farmacogn. 2007, 17, 231.

12. European Pharmacopoeia, $6^{\text {th }}$ ed., Council of Europe: Strasbourg, 2008.

13. http://www.anvisa.gov.br/hotsite/cd_farmacopeia/index.htm, accessed March 2011.

14. Farmacopeia Portuguesa, $8^{\text {th }}$ ed., Infarmed: Lisboa, 2005; British Pharmacopeia 2009, London: The Stationery Office, 2008.

15. Glasl, H.; Dtsch. Apoth. Ztg. 1983, 123, 1979.

16. Turkman, N.; Sari, F.; Velioglu, Y. S.; Food Chem. 2006, 99, 835; Tawaha, K.; Food Chem. 2007, 104, 1372.

17. Pelillo, M.; Cuvelier, M. E.; Biguzzi, B.; Toschi, T. G.; Berset, C.; Lercker, G.; J. Chromatogr., A 2004, 1023, 225.

18. ICH; International Conference on Harmonization of Technical Requeriments for Registration of Pharmaceuticals for Human Use, Q2B(R1): Guideline on Validation of Analytical ProcedureMethodology, 2005; Agência Nacional de Vigilância Sanitária ANVISA; RE No. 899, on 29/5/2003: Guia para Validação de Métodos Analíticos e Bioanalíticos, Ministério da Saúde: Brasília, 2003.
19. Leal, A. A. X.; Henriques, C. A.; Luna, A. S.; Rev. Analytica 2008, 32, 28.

20. Rocha, F. R. P.; Teixeira, L. S. G.; Quim. Nova 2004, 27, 807.

21. Pelozo, M. I. G.; Cardoso, M. L. C.; Mello, J. C. P.; Braz. Arch. Biol. Technol. 2008, 51, 447; Silva-Corazza, P. E. R.; Lopes, G. C.; DiCiaula, M. C.; Lima, M. M. S.; Palazzo de Mello, J. C.; Lat. Am. J. Pharm. 2010, 29, 830 .

22. Singleton, V. L.; Orthofer, R.; Lamuela-Raventos, R. M.; Methods in Enzymol. 1999, 299, 152.

23. Chun, O. K.; Kim, D.; Food Res. Int. 2004, 37, 337.

24. Ribani, M.; Bottoli, C. B. G.; Collins, C. H.; Jardim, I. C. S. F.; Melo, L. F. C.; Quim. Nova 2004, 27, 771.

25. Bruce, P.; Minkkinen, P.; Riekkola, M.-L.; Mikrochim. Acta 1998, 128, 93. 